\title{
Multifocal fibrosclerosis associated with suprasellar and macular lesions
}

\author{
D. J. BRAZIER AND M. D. SANDERS
}

From the Department of Ophthalmology, St Thomas's Hospital, London SE1, and the Department of Neuro-Ophthalmology, National Hospital for Nervous Diseases, Queen Square, London WC1

SUMmaRY Multifocal fibrosclerosis is a term used to denote a combination of similar fibrous disorders occurring at different anatomical sites and including idiopathic mediastinal and retroperitoneal fibrosis, sclerosing cholangitis, Riedel's thyroiditis, and orbital pseudotumour. This paper reports a patient, known to have retroperitoneal and testicular fibrosis, who suffered visual loss resulting from marked changes in the macular region of one eye and suprasellar extension of a mass in the pituitary fossa. These lesions appear to represent very uncommon manifestations of multifocal fibrosclerosis.

It appears that Barrett ${ }^{1}$ was the first to suggest that mediastinal and retroperitoneal fibrosis, Riedel's thyroiditis, and pseudotumour of the orbit were linked by similar pathological features. He gave credit to Tubbs, ${ }^{2}$ who had earlier described a patient with obstruction of the superior vena cava by mediastinal fibrosis and obstruction of the inferior vena cava by fibrosis of the para-aortic tissues. Tubbs thus recognised the features of retroperitoneal fibrosis 2 years before the condition was formally described by Ormond. ${ }^{3}$ The name multifocal fibrosclerosis was suggested by Comings et al.,${ }^{4}$ although other authors have preferred idiopathic systemic fibrosis $^{5}$ and multisystem fibrosis. ${ }^{6}$

Confirmation of the association of orbital pseudotumour with other components of multifocal fibrosclerosis has been provided in several case reports since Barrett's original suggestion. Comings et al. ${ }^{4}$ described 2 brothers, by a consanguinous marriage, who between them suffered from mediastinal and retroperitoneal fibrosis, sclerosing cholangitis, Riedel's thyroiditis, Dupuytren's contracture, and pseudotumour of the orbit (diagnosed on the basis of proptosis and restriction of eye movements without orbital biopsy). Orbital pseudotumour associated with retroperitoneal fibrosis has been described on at least one other occasion.' Several authors have noted orbital pseudotumour with Riedel's thyroiditis, ${ }^{8-11}$

Correspondence to Mr M. D. Sanders, FRCS, Department of Neuro-Ophthalmology, National Hospital for Nervous Diseases, Queen Square, London WC1N 3BG. and Wenger et al. ${ }^{12}$ have reported an association with sclerosing cholangitis. Little can be added to the excellent account of the clinical features of orbital pseudotumour and its place in multifocal fibrosclerosis by Jakobiec and Jones. ${ }^{13}$

Other reported disorders in multifocal fibrosclerosis include pelvic fibrosis, ${ }^{14}$ fibrosis of the testicle,${ }^{15}$ subcutaneous tissues, ${ }^{16}$ and intestinal mesentery, ${ }^{17}$ and Peyronie's disease of the penis. ${ }^{6}$

\section{Case report}

A 26-year-old man, of Spanish origin presented in 1974 with a 6-month history of tenderness and enlargement of the left breast. He had lived and worked in a horticultural nursery since his arrival in Britain 4 years earlier. He was a nonsmoker who took alcohol occasionally. There was no history of drug or chemical exposure. The patient and 3 siblings had pes cavus.

On examination he had left gynaecomastia with a well developed nipple but no axillary adenopathy. Abdominal examination was normal except for some enlargement and firmness of the right testis. Investigation showed an elevated ESR (37 and 42 $\mathrm{mm} / \mathrm{h}$ on different occasions). Intravenous urography showed a left hydronephrosis, and retrograde pyelography showed complete obstruction of the left ureter at the level of the third lumbar vertebra. At laparotomy the left kidney was found to be embedded in a mass of dense fibrous tissue on the posterior 


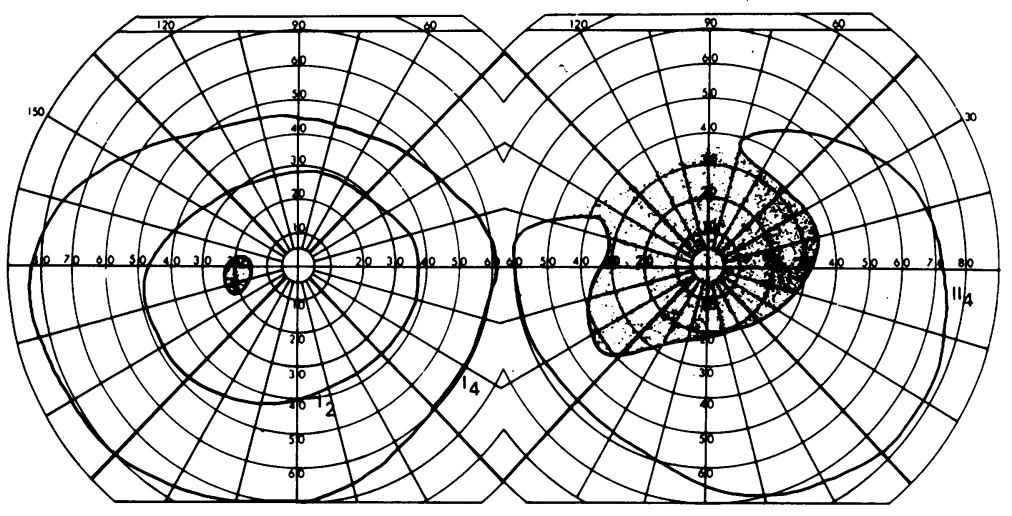

Fig. 1 Goldmann perimetry. There is a large right centrocaecal scotoma.

abdominal wall. Fibrosis around the pelviureteric junction was responsible for the obstruction. The ureter could not be freed by dissection. Biopsies of the region showed benign fibrous tissue infiltrated with lymphocytes and plasma cells. Biopsies of adjacent lymph nodes were normal. A right testicular biopsy specimen taken at the same time consisted of an irregular mass of dense fibrous tissue containing large foamy macrophages and foci of lymphocytes and eosinophils. In certain areas atrophied testicular tissues were visible. No intra-abdominal malignancy was detected either at laparotomy or on histological examination of biopsy material. A diagnosis of idiopathic retroperitoneal fibrosis was made and treatment with systemic steroids begun.

Six months later he complained of gradual painless visual loss in the right eye. The reduction of vision increased during the succeeding weeks, and he was subsequently admitted to the National Hospital, Queen Square. By this time he had developed generalised headache, which was sometimes more marked on waking. There were no

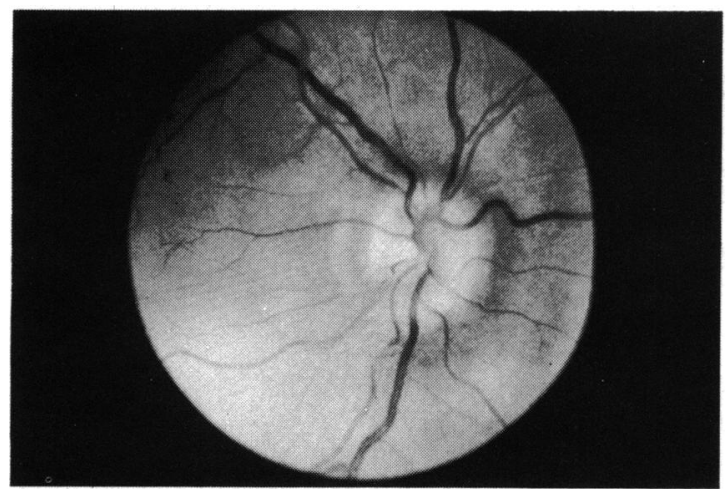

Fig. 2 Right optic disc from colour photograph. Retinal folds are seen running from the temporal margin of the disc. sensory or motor symptoms and no speech disturbance.

On examination there was bilateral gynacomastia, more marked on the right. Some abdominal fullness was noted adjacent to the recent scar. Ophthalmic examination revealed corrected visual acuities to be right counting fingers and left $6 / 6$. The pupils were equal, with a marked right afferent defect. Eye movements were normal and there was no proptosis. Corneal sensation was normal. Anterior chambers were quiet. Visual field examination by the Goldmann perimeter showed a large centrocaecal scotoma on the right but no abnormality on the left (Fig. 1). The left fundus appeared normal. There was some swelling of the right optic disc and extensive serous detachment of the retina at the posterior pole. Retinal folds were seen running horizontally from the temporal margin of the disc (Fig. 2). The pigment epithelium deep to the detached retina was generally atrophic (Fig. 3) and in some areas elevated.

Fluorescein angiography of the right eye showed a transmission defect in the area of pigment epithelial change during the arterial and early arteriovenous

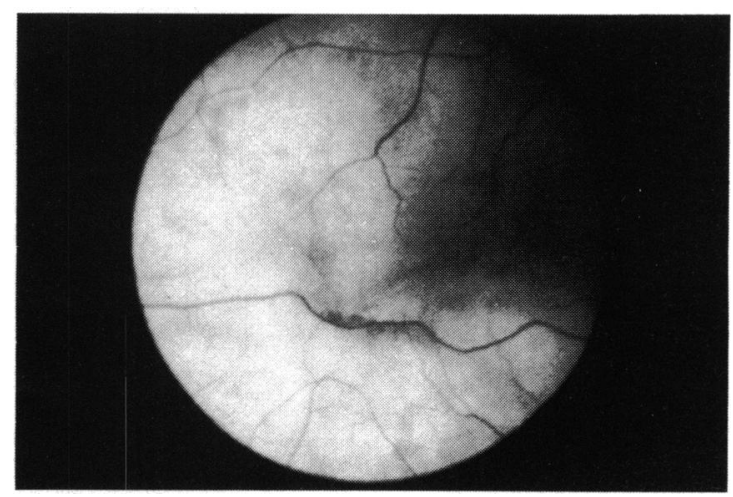

Fig. 3 Right macular region from a colour photograph. There is serous detachment of the retina in the field of this photograph. The pigment epithelium has undergone extensive atrophy. 


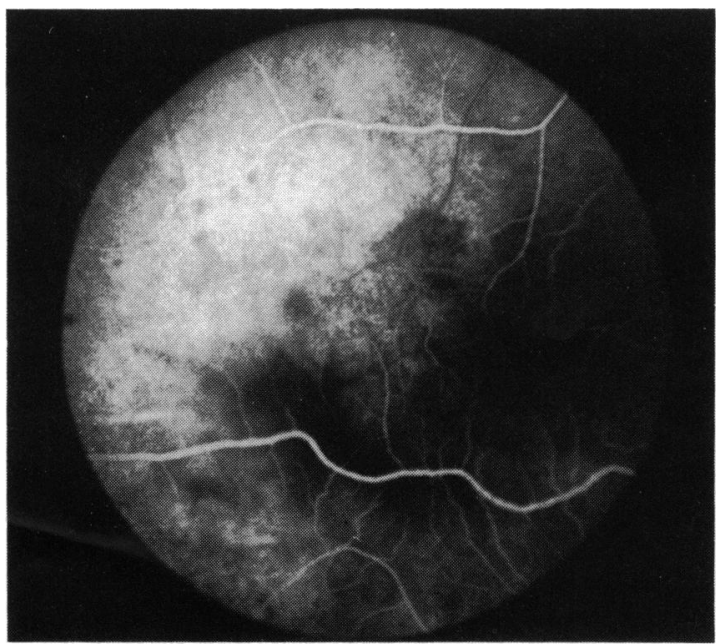

Fig. 4 Early arteriovenous phase fluorescein angiogram of right macular region. There is a transmission defect corresponding to the area of pigment epithelial atrophy.

phases (Fig. 4). Later in the run hyperfluorescence occurred as fluorescein reached the subretinal space (Fig. 5). In the late phase the right disc showed hyperfluorescence which was not present on the left (Figs. 6 and 7 respectively).

A number of radiological investigations were performed. Chest $x$-ray was normal. Skull $x$-ray showed abnormal calcification within the pituitary fossa which was neither eroded nor enlarged (Fig. 8). A CT scan showed a calcified mass arising from the pituitary fossa but not encroaching on the third

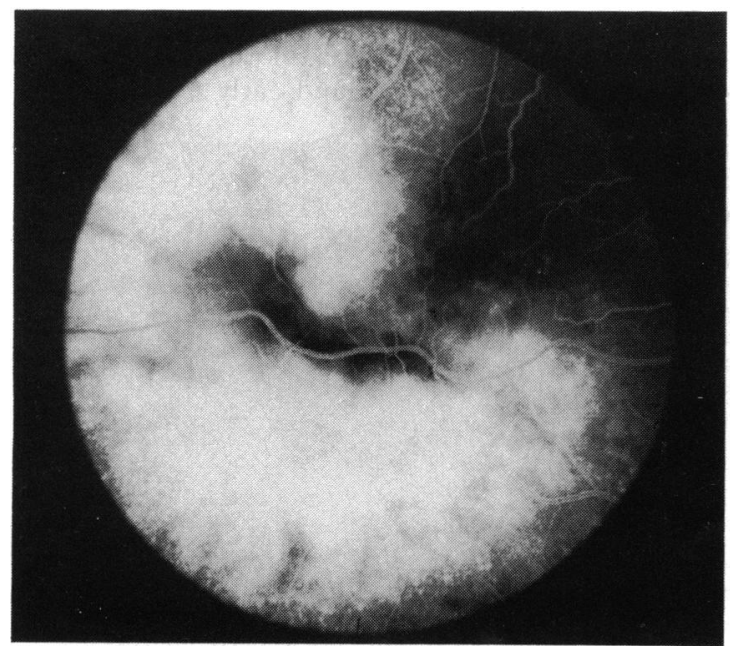

Fig. 5 Late venous phase angiogram, right eye, shows increasing hyperfluorescence as the fluorescein reaches the subretinal space.

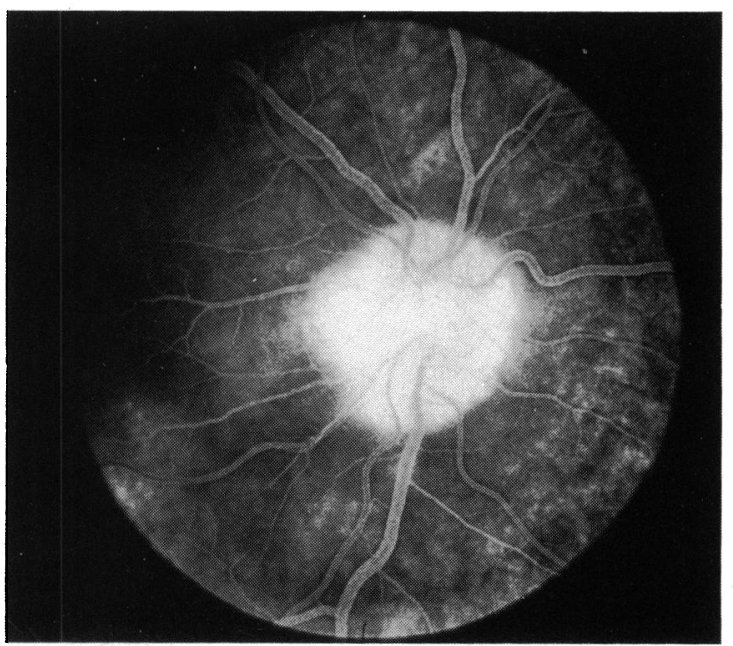

Fig. 6 Late phase angiogram, right eye, shows hyperfluorescence of the optic disc, more marked on the temporal side.

ventricle. The rest of the ventricular system was also normal in size and position. Bilateral carotid angiography showed upward displacement of the horizontal portion of both anterior cerebral arteries consistent with the $1 \mathrm{~cm}$ suprasellar extension of the mass, confirmed by air encephalography.

At right frontal craniotomy the right optic nerve was found to be grey and applied to an extremely tough yellow tumour lying medial to it. The tumour was not cystic and appeared almost avascular. It could not be sucked out and was therefore removed

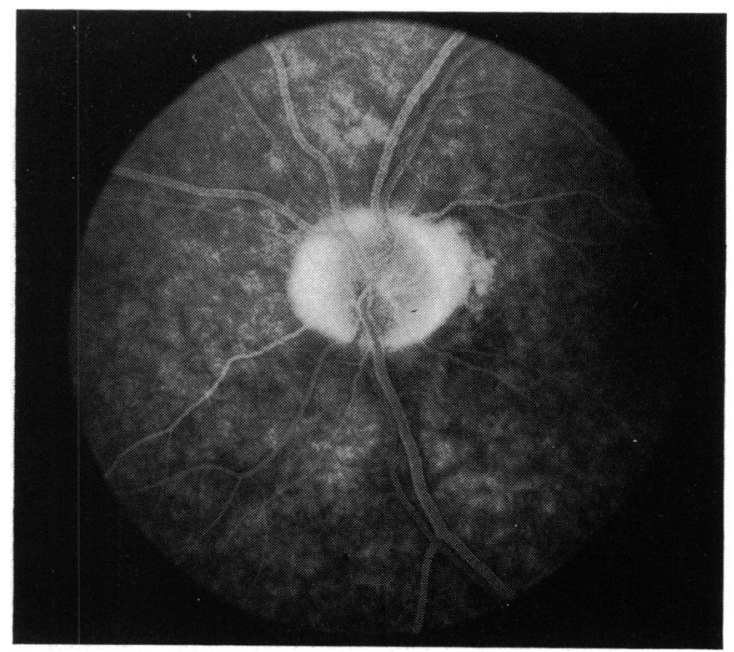

Fig. 7 Late phase angiogram, left eye. Similar hyperfluorescence of the optic disc is not seen in this eye. 


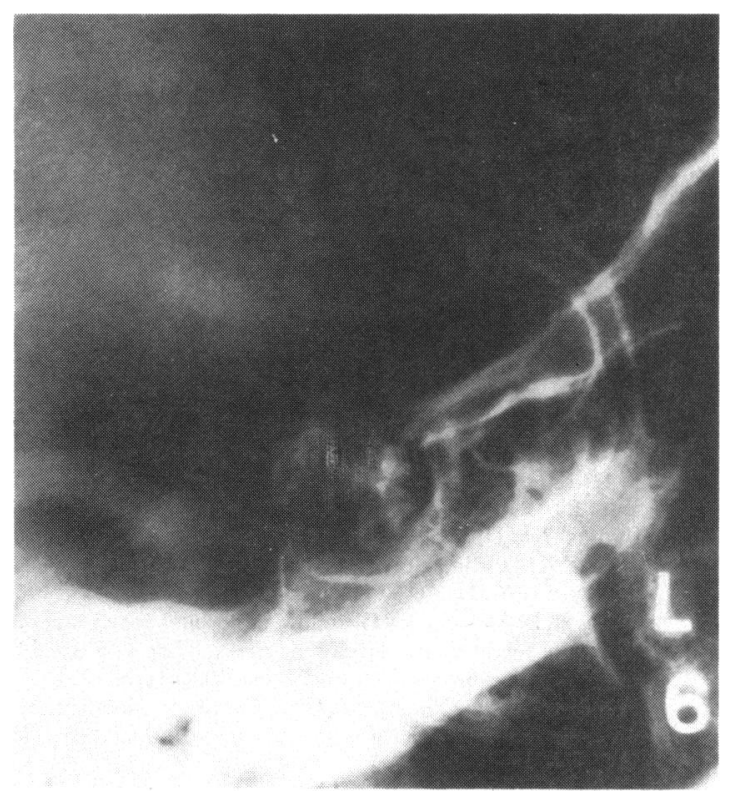

Fig. 8 Magnified lateral radiograph of the pituitary fossa. Abnormal calcification is present within the fossa which does not appear eroded or expanded.

piecemeal. A projection to the right below the optic nerve was removed without apparent damage to the nerve or adjacent anterior cerebral artery.

On pathological examination the intracranial lesion was found to be firm and calcified. Most of it consisted of collagen which was very dense in some areas and infiltrated with large foamy cells in others (Fig. 9). Plasma cells, lymphocytes, eosinophils, and fibro- blasts were scattered among the collagen. No epithelioid or Langhans giant cells were seen.

In the postoperative period the patient was reported to have bilateral total visual loss with dilated nonreacting pupils. The left visual acuity improved to counting fingers before discharge. A full account of the subsequent endocrinological investigation and treatment of this patient has been published by Grossman et al. ${ }^{18}$

\section{Discussion}

Precise classification of the intracranial lesion on a histopathological basis is not possible. The absence of epithelioid cells and Langhans giant cells excludes tuberculosis and sarcoidosis. The paucity of eosinophils is very much against a parasitic cause. In the absence of Langhans giant cells and destructive bony changes Wegener's granulomatosis may also be excluded. The possibility that the lesion represented a manifestation of histiocytosis $\mathrm{X}$ was also discussed but thought unlikely. Ultimately, it can only be concluded that the tissue came from a chronic inflammatory lesion of unknown cause. It is of great interest that the intracranial lesion shared many features with the retroperitoneal biopsy specimens and also conformed with Mitchinson's description of the histological features of retroperitoneal fibrosis. ${ }^{19}$

The intrasellar mass with superior extension does not explain all the ophthalmic signs. Certainly there was compression of the right optic nerve, confirmed at craniotomy, which might have been sufficient to explain the visual loss and afferent pupillary defect. The visual loss is equally well explained by the changes

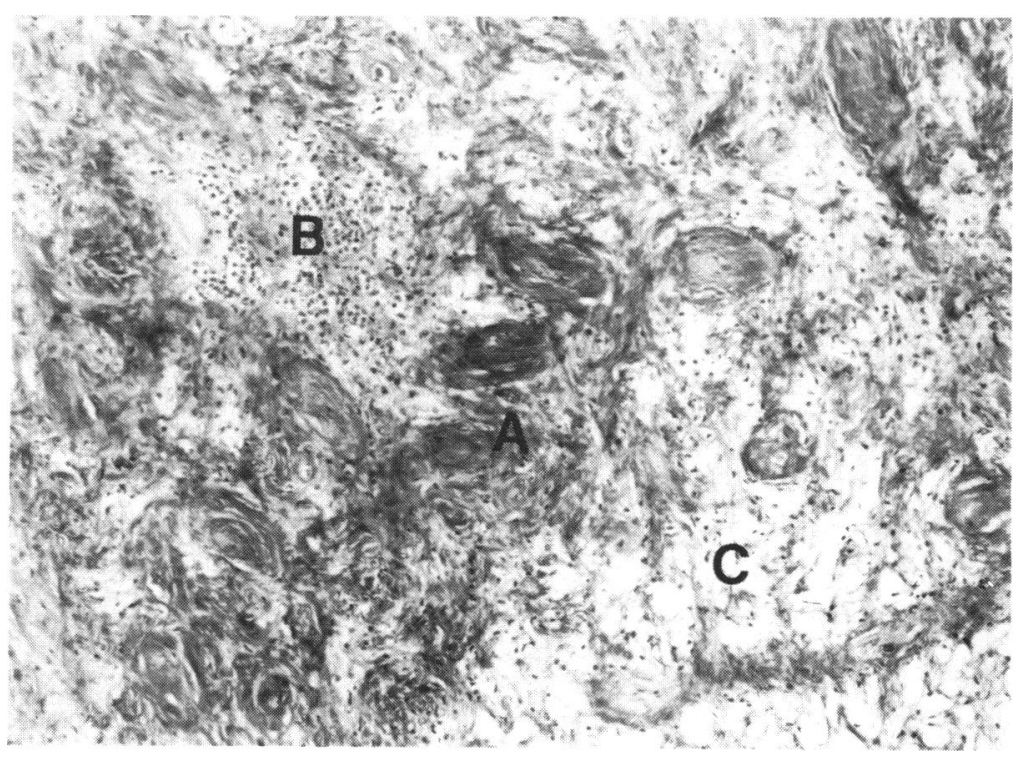

Fig. 9 Section of the intracranial lesion. Dense bundles of collagen (A) are infiltrated with inflammatory cells $(\mathrm{B})$. Many large foamy cells are present (C). (Haematoxylin and van Gieson, $\times 115$ ). 
at the right posterior pole, though the cause of the nonrhegmatogenous retinal detachment is not immediately obvious. The possibility of an orbital pseudotumour associated with retroperitoneal fibrosis warrants consideration, though must be regarded as most unlikely without proptosis or loss of eye movements.

The visual loss postoperatively occurred despite the usual extreme caution in manipulation of the optic nerves and chiasm during surgery. It is probable that only minimal damage was required to extinguish function in the compromised right nerve.

We have located only one other report of visual disturbance associated with an intrasellar lesion in a patient with multifocal fibrosclerosis. Hissong and Freimanis $^{20}$ reported a 16-year-old male who presented with a short history of blurred vision and headaches. On examination he had a bitemporal field defect. Skull $x$-ray showed an enlarged sella but no abnormal calcification. At surgery the mass was seen to extend upwards and backwards from the fossa. Histological examination suggested that the lesion was a meningioma, though the authors point out that the absence of the characteristic tumour circulation on carotid angiography weighed against this. The patient died 16 months later, when post-mortem examination revealed retroperitoneal and pericardial fibrosis. Many other organs showed fibrotic changes.

As yet there is no firm evidence regarding the cause of multifocal fibrosclerosis. Comings et al. ${ }^{4}$ suggested a genetic factor in the brothers they reported, and more recently an association of retroperitoneal fibrosis and HLA B27 has been reported. ${ }^{21-24}$ The relationship of methysergide to retroperitoneal fibrosis is well documented..$^{25-27}$ Koep and Zuidema ${ }^{28}$ reported associated malignancy in $7.9 \%$ of 481 cases of retroperitoneal fibrosis. The failure to identify a cause in the majority of cases makes specific systemic treatment impossible.

We wish to thank Mr Norman Grant for permitting us to report the case history of a patient under his care and Professor Leo Duchen for allowing us to publish a photograph of histological material prepared in the Department of Neuropathology. We also thank DrF. Scaravilli, who reviewed the original histological specimens and advised us on interpretation of their pathological features, Miss Josephine Lace, who typed the manuscript, and Mr Richard Dewhirst who prepared the illustrations.

\section{References}

1 Barrett NR. Idiopathic mediastinal fibrosis. Br J Surg 1958; 46: 207-18.
2 Tubbs OS. Superior vena caval obstruction due to chronic mediastinitis. Thorax 1946; 1: 247-56.

3 Ormond JK. Bilateral ureteral obstruction due to envelopment and compression by an inflammatory retroperitoneal process. $J$ Urol 1948; 59: 1072-9.

4 Comings DE. Skubi KB. Van Eyes J. Motulsky AG. Familial multifocal fibrosclerosis. Ann Intern Med 1967; 66: 884-92.

5 Mitchinson MJ. Systemic idiopathic fibrosis and systemic WeberChristian disease. J Clin Pathol 1965; 18: 645-9.

6 Palmer PE. Wolfe HJ. Kostas C-I. Multisystem fibrosis in alpha1-antitrypsin deficiency. Lancet 1978; i: 221.

7 Richards AB. Skalka HW. Roberts FJ. Flint A. Pseudotumor of the orbit and retroperitoneal fibrosis. Arch Ophthalmol 1980; 98: 1617-20.

8 Andersen SR. Seedorf HH. Halberg P. Thyroiditis with myxoedema and orbital pseudotumour. Acta Ophthalmol (Kbh) 1963: 41: 120-5.

9 Arnott EJ, Greaves DP. Orbital involvement in Riedel's thyroiditis. Br J Ophthalmol 1965; 49: 1-5.

10 Schnieder RJ. Orbital involvement in Riedel's struma. Can J Ophthalmol 1976; 11: 87-90.

11 Wilmshurst P. Melsom R. Gostelow B. Orbital pseudotumour and lacrimal involvement developing in a patient with Riedel's struma receiving steroids. Clin Endocrinol 1981; 14: 63-7.

12 Wenger J, Gingrich GW. Mendeloff J. Sclerosing cholangitis-a manifestation of systemic disease. Arch Intern Med 1965; 116: 509-14.

13 Jakobiec FA. Jones IS. Orbital inflammations. In: Duane TD. ed. Clinical ophthalmology. Hagerstown: Harper and Row, 1980: 2: chapter 35 .

14 Copland RFP. Wilson S. Snell ME. Idiopathic pelvic fibrosis: a variant of retroperitoneal fibrosis? Urology 1981; 18: 567-71.

15 Fraser I. Testicular involvement in the retroperitoneal fibrosis syndrome. Br J Surg 1976; 63: 107-9.

16 Coopersmith NH. Appelman HD. Multifocal fibrosclerosis with subcutaneous involvement. Am J Clin Pathol 1971; 55: 369-76.

17 Binder SC, Deterling RA. Mahoney SA. Patterson JF. Wolfe HJ. Systemic idiopathic fibrosis. Am J Surg 1972; 124: 422-30.

18 Grossman A. Gibson J. Stansfield AG, Besser GM. Pituitary and testicular fibrosis in association with retroperitoneal fibrosis. Clin Endocrinol 1980; 12: 371-4.

19 Mitchinson MJ. The pathology of idiopathic retroperitoneal fibrosis. J Clin Pathol 1970; 23: 681-9.

20 Hissong SL. Freimanis AK. Retroperitoneal fibrosis: extraperitoneal lesions. Am J Radiol 1969; 107: 776-86.

21 Case records of the Massachusetts General Hospital (case 131976). N Engl J Med 1976; 274: 712-8.

22 Willscher MK. Novicki DE, Cwazka WF. Association of HLSB27 antigen with retroperitoneal fibrosis. J Urol 1978; 120: 631-3.

23 Littlejohn GA, Keystone EC. The association of retroperitoneal fibrosis with systemic vasculitis and HLA-B27.J Rheumatol 1981; 8: 665-9.

24 Mansell MA. Watts RWE. Retroperitoneal fibrosis and scleroderma. Postgrad Med J 1980; 56: 730-3.

25 Graham JR. Methysergide for prevention of headache. N Engl J Med 1964; 270: 67-72.

26 Utz DC. Rooke ED. Spittell JA, Bartholomew LG. Retroperitoneal fibrosis in patients taking methysergide. JAMA 1965; 191: 983-5.

27 Graham JR, Suby HI. Le Compte PR. Sadowsky NI. Fibrotic disorders associated with methysergide therapy for headache. $N$ Engl J Med 1966: 274: 359-68.

28 Koep L. Zuidema GD. The clinical significance of retroperitoneal fibrosis. Surgery 1977; 81: 250-7. 